\title{
PROFILE AND TREATMENT OF PATIENTS WITH VOGT-KOYANAGI- HARADA SYNDROME IN A TERTIARY REFERRAL CENTER
}

Fernanda Lourenço Macagnani ${ }^{1, \star}$, Camila Avila Megda Cabianca ${ }^{1}$, Leticia Cezar Araujo ${ }^{1}$, Amanda Alexia Rodrigues Vieira ${ }^{1}$, Maria Thereza Gomes Caldeira ${ }^{1}$, João Marcello Fortes Furtado ${ }^{1}$, Rodrigo de Oliveira ${ }^{1}$, Rodrigo Luppino-Assad ${ }^{1}$

1.Universidade de São Paulo, Ribeirão Preto (SP), Brazil.

*Corresponding author: fernanda_macagnani@hotmail.com

\section{BACKGROUND}

To analyze patients profile diagnosed with Vogt-Koyanagi-Harada syndrome (VKHS) in a joint outpatient clinic for rheumatology and ophthalmology at a tertiary hospital, as well as the proposed treatment and its effectiveness.

\section{METHODS}

This is a retrospective cross-sectional observational study, in which 147 charts were analyzed. Of these, 33 patients had a diagnosis of VKHS. After review, 4 patients were removed from the study (2 of whom had no confirmed diagnosis of VKHS, 1 due to lack of data and 1 due to the onset of the disease after eye surgery). They were grouped according to the form of presentation of the disease in probable, complete and incomplete. The first group was defined by ocular involvement, the second by eye disease associated with auditory/neurological or cutaneous alterations and the third by all the manifestations described previously.

\section{RESULTS}

Eleven (37.93\%) patients had probable VKHS, 15 (51.72\%) had the incomplete form and $3(10.35 \%)$ had the complete form of the disease. Twenty-four (82.76\%) patients used prednisone, 16 (55.17\%) methotrexate, 16 (55.17\%) azathioprine, 10 (34.48\%) methylprednisolone, another 5 (17.24\%) cyclosporine, 4 (13.79\%) cyclophosphamide and 1 (3.45\%) sulfasalazine. One (3.45\%) patient was using immunobiological therapy (infliximab). Twenty-six (89.66\%) patients were in remission and $3(10.34 \%)$ were in disease activity.

\section{CONCLUSION}

The study concluded that most patients have an incomplete form and the complete form is rarer. In addition, maintenance treatment with synthetic immunosuppressive medications is necessary. Immunobiological therapy is instituted in exceptional cases.

\section{KEYWORDS}

Vogt-Koyanagi-Harada, Uveitis, Panuveitis. 